\title{
The association between dietary intake of magnesium and psychiatric disorders among Iranian adults: a cross-sectional study
}

\author{
Javad Anjom-Shoae ${ }^{1,2}$, Omid Sadeghi ${ }^{1,2} \dagger$, Ammar Hassanzadeh Keshteli ${ }^{3}$, Hamid Afshar ${ }^{4}$, \\ Ahmad Esmaillzadeh ${ }^{2,5,6 *}$ and Peyman Adibi ${ }^{7}$ \\ ${ }^{1}$ Students' Scientific Center, Tehran University of Medical Sciences, PO Box 1417755331, Tehran, Iran \\ ${ }^{2}$ Department of Community Nutrition, School of Nutritional Sciences and Dietetics, Tehran University of Medical Sciences, \\ PO Box 141556117, Tehran, Iran \\ ${ }^{3}$ Department of Medicine, University of Alberta, PO Box 7-142, Edmonton, Alberta, Canada \\ ${ }^{4}$ Psychosomatic Research Center, Isfahan University of Medical Sciences, PO Box 81745-151, Isfahan, Iran \\ ${ }^{5}$ Obesity and Eating Habits Research Center, Endocrinology and Metabolism Molecular-Cellular Sciences Institute, \\ Tebran University of Medical Sciences, PO Box 1414413137, Tehran, Iran \\ ${ }^{6}$ Department of Community Nutrition, School of Nutrition and Food Science, Isfahan University of Medical Sciences, \\ PO Box 8174673461, Isfahan, Iran \\ ${ }^{7}$ Integrative Functional Gastroenterology Research Center, Isfahan University of Medical Sciences, PO Box 81745-151, \\ Isfahan, Iran
}

(Submitted 4 November 2017 - Final revision received 7 May 2018 - Accepted 18 May 2018 - First published online 2 August 2018)

\section{Abstract}

Findings from clinical trials on the effect of Mg supplementation on depression and anxiety are not generalisable to the community owing to high-dose intervention in short-term periods. Limited observational data are available linking dietary intake of $\mathrm{Mg}$ and psychiatric disorders. We aimed to investigate the association between dietary intake of $\mathrm{Mg}$ and psychiatric disorders in a large cross-sectional study on Iranian adults. A total of 3172 Iranian adults (with an age range of $18-55$ years) were included in this study. Data on dietary intakes were collected using a validated dish-based 106-item semi-quantitative FFQ. To assess depression and anxiety, an Iranian validated version of the Hospital Anxiety and Depression Scale was used. Furthermore, psychological distress was examined using the General Health Questionnaire. The mean age of men and women was 38.4 (sD 8.2) and 35.1 (SD 7.4) years, respectively. In unadjusted analyses, we found that higher dietary Mg intake was associated with lower odds of anxiety among women (OR $0.61 ; 95 \% \mathrm{CI} 0 \cdot 41,0 \cdot 90$ ), such that after taking potential confounders into account women in the highest quintile of $\mathrm{Mg}$ intake had a $39 \%$ lower odds of anxiety compared with those in the lowest quintile (OR 0.61; $95 \%$ CI 0.40, 0.93). Moreover, deficient Mg intake was positively associated with anxiety among all women (OR $1 \cdot 80 ; 95 \%$ CI $1 \cdot 19,2 \cdot 72)$ and also normal-weight women (OR 1.73; $95 \%$ CI 1.01, 2.95). In addition, a significant inverse association was found between dietary Mg intake and depression among normal-weight men (OR 0.45; $95 \%$ CI 0.20, 0.99) and overweight women (OR 0.45; 95\% CI 0.24, 0.85). In conclusion, dietary intake of $\mathrm{Mg}$ was inversely associated with depression and anxiety. However, such findings were not seen for psychological distress.

Key words: Anxiety: Depression: Magnesium: Psychological distress

Psychiatric disorders affect millions of people around the world ${ }^{(1)}$. Depression and anxiety are the most commonly diagnosed psychiatric conditions, influencing global health, quality of life, life expectancy and economy ${ }^{(2-4)}$. It is estimated that 4.7 and $7.3 \%$ of population, around the world, suffer from depression and anxiety, respectively ${ }^{(5,6)}$. In Iran, according to national statistics, about $20 \cdot 8$ and $20 \%$ of Iranian adults are affected, respectively ${ }^{(7)}$.

In the aetiology of depressive disorders, the simultaneous occurrence of various factors including personal, genetic and environmental factors seem to be important ${ }^{(8)}$. Much evidence is available on the role of diet in the development of depression and anxiety ${ }^{(9)}$. For instance, consumption of green leafy vegetables, legumes, nuts, seeds and whole grains was associated with lower odds of depression ${ }^{(10-14)}$. Although the exact component of these foods affecting depression and anxiety is unknown, all these foods and food groups are rich sources of $\mathrm{Mg}$, which plays an important role in the nervous system via its actions on the release and metabolism of neurotransmitters and

Abbreviation: DS-FFQ, dish-based 106-item semi-quantitative FFQ.

* Corresponding author: A. Esmaillzadeh, fax +98 21 88984861, email a-esmaillzadeh@tums.ac.ir

$\dagger$ First co-author. 
other mechanisms ${ }^{(15)}$. Several clinical trials had assessed the effect of high doses of $\mathrm{Mg}$ supplementation on depression in a short time period ${ }^{(16,17)}$. Findings from these investigations are not easily generalisable to routine lifestyle. Little attention has been paid on usual intakes of Mg. In a Finnish cohort study, an inverse relationship between dietary $\mathrm{Mg}$ intake and depression has been demonstrated ${ }^{(18)}$, whereas a prospective study failed to find any conclusive evidence on this association $^{(19)}$. Moreover, a meta-analysis in this regard has indicated that moderate $\mathrm{Mg}$ intake may be inversely associated with the risk of depression ${ }^{(20)}$. Furthermore, several studies have shown a significant higher risk of depression in hypomagnesaemic individuals $^{(20)}$, whereas others have not reached such findings ${ }^{(21,22)}$. Therefore, data in this regard are conflicting. Overall, it seems that further studies are required to shed light on this issue.

Prior investigations on the association between dietary $\mathrm{Mg}$ intake and mental disorders have mostly been performed in Western nations, and limited studies have been carried out in this regard in Middle East countries. Examining the association between dietary $\mathrm{Mg}$ intake and mental disorders is particularly relevant for the Middle Eastern region where the prevalence of mental disorders is alarmingly high and the consumption of legumes, nuts and vegetables as the main dietary sources of $\mathrm{Mg}$ is low ${ }^{(6,7)}$. Furthermore, previous studies on the association between dietary $\mathrm{Mg}$ intake and mental disorders were conducted without controlling for potential confounding variables. With controlling for confounders, this study aimed to examine the association between dietary $\mathrm{Mg}$ intake and mental disorders among a large population of Iranian adults.

\section{Methods \\ Participants}

This cross-sectional study was carried out within the framework of Studying the Epidemiology of Psycho-Alimentary Health and Nutrition (SEPAHAN) project, which was performed on a large population of Iranian adults working in fifty different health centres in Isfahan, Iran. Detailed information about SEPAHAN project has been published elsewhere ${ }^{(23)}$. Briefly, collecting data at two separate main phases in this project leads to higher accuracy of collected data and participation rate. At the first phase, data on demographic variables along with dietary intakes were collected for 8691 people. At the second phase, data regarding psychological health were collected. By merging data from both phases, we had complete information for 4763 people. In the current analysis, we excluded participants who did not have total energetic intakes in the range of $3347-$ $17573 \mathrm{~kJ} / \mathrm{d}(800-4200 \mathrm{kcal} / \mathrm{d})$ as under-reporters and overreporters of energy intake ( $n$ 787). In addition, individuals with missing data on psychological, demographic, anthropometric and dietary information were excluded ( $n$ 130). After these exclusions, a data set of 3172 participants including 1398 men and 1774 women was supplied for this study. All participants provided signed informed written consent forms. The whole project of SEPAHAN was ethically approved by the Bioethics Committee of Isfahan University of Medical Sciences, Isfahan, $\operatorname{Iran}^{(23)}$

\section{Dietary intake assessment}

The usual dietary intakes of participants were assessed by a validated Willett-format dish-based 106-item semi-quantitative FFQ (DS-FFQ), which was designed particularly for Iranian adults $^{(24)}$. Details on design, food items and validity of this FFQ have been reported previously ${ }^{(25)}$. In brief, first we prepared a comprehensive list of foods and dishes commonly consumed by Iranian adults. Then, we chose those that were nutrient-rich, consumed reasonably often or that contributed to betweenperson variations from this list. Selection of a food as a usual food item was done according to dietary records and recalls that had been collected in our prior investigations. Finally, 106 food items in five different categories existed in this questionnaire: (1) mixed dishes (cooked or canned, twenty-nine items); (2) carbohydratebased foods (different types of bread, cakes, biscuits and potato, ten items); (3) dairy products (dairies, butter and cream, nine items); (4) fruit and vegetables (twenty-two items); and (5) miscellaneous food items and beverages (including sweets, fast foods, nuts, desserts and beverages, thirty-six items).

We asked individuals to report their dietary intakes of foods and mixed dishes based on nine multiple-choice frequency response categories varying from 'never or less than once a month' to 'twelve or more times per day.' The frequency response categories for all the food items were not constant and varied from six to nine choices. We omitted the high-frequency categories for foods consumed infrequently, as well as increasing the number of multiple-choice categories for common foods with a high consumption. Furthermore, in order to increase the accuracy of the responses, we used the most popular serving sizes familiar to Iranian adults. Finally, we calculated the daily intakes of all foods and dishes and converted them to grams per day using household measures ${ }^{(26)}$. Next, in order to compute the daily energy and nutrient intakes (particularly $\mathrm{Mg}$ ) of each participant, we summed up the energy and nutrient contents of all foods and dishes. Energy and nutrients contents of each food were obtained using the US Department of Agriculture's national nutrient databank ${ }^{(27)}$. Earlier studies have indicated that data on food groups' intake, as well as nutrient intake, from this questionnaire provide reasonably valid data of dietary intakes ${ }^{(28-31)}$. Although the FFQ was fulfilled based on last year's dietary intakes of participants, this questionnaire provided data about usual and long-term (more than 1 year) dietary intakes.

The validity of the DS-FFQ was evaluated in a subgroup of 200 randomly selected participants of the SEPAHAN project ${ }^{(25,32)}$. All participants in the validation study completed the DS-FFQ at study baseline and 6 months later. During this validation study, 3-d detailed dietary records, which were used as gold standard, were reported by individuals. According to findings from this study, the DS-FFQ could constitute reasonably valid and reliable measures of long-term dietary intakes in Iranian population; for instance, dietary carbohydrate intake estimated from DS-FFQ was significantly correlated with value obtained from the average of 3-d dietary records ( $r$ 0.81). Such correlation coefficients were also seen for other food groups and nutrients including $\mathrm{Mg}(r$ 0.61), proteins $(r$ 0.72) and legume and nut consumption ( $r$ 0.69). 


\section{Psychological profile assessment}

Anxiety and depression were assessed by the Iranian validated version of the Hospital Anxiety and Depression Scale, which provided valid measures of mental health on the basis of a previous study ${ }^{(33)}$. This scale is a brief and useful questionnaire to measure psychiatric disorders in addition to symptom and severity of anxiety disorders and depres$\operatorname{sion}^{(33)}$. It contains fourteen items with a four-point scale for each item and consists of two subscales: anxiety and depression; higher scores indicate the greater degree of anxiety and depression. The possible score range is from 0 to 21 for each subscales. Scores of 8 or more on either subscale were considered to indicate the presence of psychiatric disorders and scores of 0-7 were defined as 'normal' in the current study ${ }^{(33)}$. Overall, our previous investigations revealed that the questionnaire provides relatively valid measures of mental health ${ }^{(33)}$.

To assess psychological distress, we used the Iranian validated version of the General Health Questionnaire (GHQ), which contained twelve items ${ }^{(34)}$. Each item constitutes a fourpoint rating scale (less than usual, no more than usual, rather more than usual or much more than usual). We used the bimodal scoring method ( $0-0$ to $1-1)$ in order to calculate the total score of psychological distress for each participant. The total scores in this method range from 0 to 12 ; higher scores indicate a greater degree of psychological distress ${ }^{(35)}$. In our study, we considered the score of 4 or more as having psychological distress. A validation study on 748 Iranian adults showed a significant inverse correlation between the GHQ-12 and global quality-of-life scores $(r-0.56, P<0 \cdot 001)^{(35)}$.

\section{Assessment of covariates}

We used a self-reported questionnaire in order to obtain data on age, sex, marital status (single/married), education (high school diploma or below/above high school diploma), smoking status (non-smoker/former smoker/current smoker), family size ( $\leq 4 />4$ members), home ownership (owner/nonowner), gestational and lactating status, disease history (diabetes, asthma, colitis, stroke, myocardial infarction, heart failure and cancers), current use of anti-psychotic medications (including nortriptyline, amitriptyline or imipramine, fluoxetine, citalopram, fluvoxamine and sertraline) and dietary supplements (including intake of $\mathrm{Fe}, \mathrm{Ca}$, vitamins and other dietary supplements). Assessing physical activity of study participants was carried out via a General Practice Physical Activity Questionnaire (GPPAQ), which is a simple validated screening tool for grading the physical activity of adults by focusing on current general activities. On the basis of the type and intensity of individual's physical activity in work hours and during the weekends, they were categorised into four groups: active ( $>3 \mathrm{~h} /$ week), moderately active (1-3h/week), moderately inactive $(<1 \mathrm{~h} /$ week) and inactive (no physical activity). The validity of the GPPAQ for assessment of habitual physical activity levels has been valuated elsewhere ${ }^{(23)}$. To gather information on anthropometric measures including weight and height, we used a self-reported questionnaire. BMI was calculated as weight in $\mathrm{kg}$ divided by the height in $\mathrm{m}^{2}$. The validity of self-reported weight and height was examined in a pilot study on 200 participants from the same population, which showed that correlation coefficients for self-reported weight and height $v$. technician-measured values were 0.95 $(P<0.001)$ and $0.83(P<0.001)$, respectively. In addition, the correlation coefficient for computed BMI from self-reported values and the one from measured values was 0.70 $(P<0 \cdot 001)$. On the basis of these results, the self-reported values of anthropometric indices supply reasonably valid measures in this study.

\section{Statistical analysis}

All statistical analyses were separately performed for men and women. First we obtained energy-adjusted intake of dietary $\mathrm{Mg}$ using residual method ${ }^{(24)}$, and then we categorised men and women by sex-specific quintiles of energy-adjusted $\mathrm{Mg}$ intake (men: Q1: $\quad<277 \mathrm{mg} / \mathrm{d}, \quad$ Q2: $\quad 277-<301 \mathrm{mg} / \mathrm{d}, \quad$ Q3: 301-<326 mg/d, Q4: 326-<358 mg/d, Q5: $\geq 358 \mathrm{mg} / \mathrm{d}$; women: Q1: $<281 \mathrm{mg} / \mathrm{d}, \mathrm{Q} 2: 281-<303 \mathrm{mg} / \mathrm{d}, \mathrm{Q} 3: 303-<325 \mathrm{mg} / \mathrm{d}, \mathrm{Q} 4:$ $325-<356 \mathrm{mg} / \mathrm{d}, \mathrm{Q} 5: \geq 356 \mathrm{mg} / \mathrm{d})$. The analyses were also performed using cut-off points of estimated average requirement (EAR) for $\mathrm{Mg}$ in men and women ((men: $320 \mathrm{mg} / \mathrm{d}$, women: $265 \mathrm{mg} / \mathrm{d}))^{(36)}$. On the basis of the Kolmogorov-Smirnov test, all variables had normal distribution. To assess differences in continuous variables (including demographic and dietary variables) across quintiles of $\mathrm{Mg}$ intake, one-way ANOVA was used, followed by pairwise post hoc tests with Bonferroni correction. The distribution of men and women in terms of categorical variables across quintiles of dietary $\mathrm{Mg}$ intake was evaluated using the $\chi^{2}$ test. Binary logistic regression in different models was applied to examine the association between dietary $\mathrm{Mg}$ intake and psychiatric disorders including depression, anxiety and psychological distress. First we included all confounders including age (continuous), marital status (single/married), education (under university/university graduated), physical activity $(<1 / \geq 1 \mathrm{~h} /$ week), smoking status (non-smoker/former smoker/current smoker), family size ( $\leq 4 />4$ members), home ownership (owner/nonowner), diabetes mellitus (yes/no), dietary supplement use (yes/ no), anti-psychotic medications (yes/no) and dietary intake of different micronutrients into models and then in the final model, which was presented, and we retained those variables that had a significant contribution. Therefore, different adjusted models for different outcomes in men and women were retained as follows: in men and for depression, model 1 included education, smoking status and anti-psychotic medications, and model 2 included model 1 plus dietary intake of energy, fat, carbohydrate and vitamin $\mathrm{B}_{2}$; for anxiety, model 1 included smoking status, antipsychotic medications and supplement use, and model 2 included model 1 plus dietary intake of energy, fibre, vitamin $B_{1}$ and $B_{2}$; and for psychological distress, model 1 included anti-psychotic medications and model 2 included model 1 plus dietary intake of energy, fibre and vitamin $\mathrm{B}_{6}$. In women and for depression, model 1 included age, marital status, education, family size, smoking status and anti-psychotic medications, and model 2 included model 1 plus dietary intake of energy and vitamin $B_{5}$; for anxiety, model 1 included marital status, education, smoking 
status, home ownership and anti-psychotic medications, and model 2 included model 1 plus dietary intake of energy, fibre, vitamin $\mathrm{B}_{1}$ and $\mathrm{B}_{2}$; and for psychological distress, model 1 included education and anti-psychotic medications, and model 2 included model 1 plus energy intake and dietary intake of vitamin $\mathrm{B}_{3}$ and $\mathrm{Fe}$. In the analyses, the first quintile of $\mathrm{Mg}$ intake was considered as the reference category. In the analysis based on EAR, participants with adequate intake of $\mathrm{Mg}$ were considered as the reference category. To determine the overall trend of OR across increasing quintiles of dietary $\mathrm{Mg}$ intake, we considered the quintiles as an ordinal variable in the logistic regression models. BMI-stratified analysis (normal weight $\left(\mathrm{BMI}<25 \mathrm{~kg} / \mathrm{m}^{2}\right)$ and overweight $\left(\mathrm{BMI} \geq 25 \mathrm{~kg} / \mathrm{m}^{2}\right)$ ) was also performed. All statistical analyses were conducted using SPSS software (version 19.0; SPSS Inc.). $P$ values were considered significant at $<0 \cdot 05$.

\section{Results}

Mean age of men and women was 38.4 (SD 8.2) and 35.1 (SD 7.4) years, respectively. Prevalence of depression, anxiety and psychological distress was $20 \cdot 4,8 \cdot 4$ and $16 \cdot 6 \%$ among men and $33 \cdot 7,17 \cdot 3$ and $27 \cdot 1 \%$ among women, respectively.

General characteristics of men and women across quintiles of energy-adjusted $\mathrm{Mg}$ intake are provided in Table 1 . Men in the highest quintile of dietary $\mathrm{Mg}$ intake were older and more likely to be obese, married, physically active, diabetic and less likely to be depressed, anxious and psychologically distressed compared with those in the lowest quintile. Compared with women in the bottom quintile, those in the top quintile of $\mathrm{Mg}$ intake were older and more likely to be overweight or obese, and less likely to be depressed, anxious and psychologically distressed.

Table 1. General characteristics of men and women across quintiles (Q) of energy-adjusted magnesium intake* (Mean values and standard deviations; percentages)

\begin{tabular}{|c|c|c|c|c|c|c|}
\hline & Q1 & Q2 & Q3 & Q4 & Q5 & $P \dagger$ \\
\hline \multicolumn{7}{|l|}{ Men } \\
\hline Age (years) & & & & & & $<0.001$ \\
\hline Mean & 36.5 & $37 \cdot 8$ & $38.7 \ddagger$ & $38.9 \ddagger$ & $40 \cdot 1 \ddagger \S$ & \\
\hline SD & 8.3 & 7.9 & 7.9 & $8 \cdot 1$ & 8.5 & \\
\hline BMI $\left(\mathrm{kg} / \mathrm{m}^{2}\right)$ & & & & & & 0.008 \\
\hline Mean & $25 \cdot 0$ & 24.9 & $25 \cdot 4$ & $25 \cdot 4$ & $25 \cdot 9 \ddagger \S$ & \\
\hline SD & $3 \cdot 2$ & 3.5 & $3 \cdot 3$ & 3.6 & 3.4 & \\
\hline Marital status (married) (\%) & $84 \cdot 1$ & $87 \cdot 3$ & $93 \cdot 8 \ddagger \S$ & $90 \cdot 4$ & $94 \cdot 2 \ddagger \S$ & 0.001 \\
\hline Education (university graduated) (\%) & 53.8 & $53 \cdot 6$ & $50 \cdot 0$ & $48 \cdot 2$ & 48.4 & 0.50 \\
\hline Physically active ( $\geq 1 \mathrm{~h} /$ week) (\%) & $18 \cdot 3$ & $18 \cdot 6$ & $12 \cdot 1$ & 23.9 & $29 \neq \S \|$ & 0.01 \\
\hline Overweight or obese (\%) & $47 \cdot 7$ & $48 \cdot 6$ & $56 \cdot 1 \ddagger$ & 52.5 & $58 \cdot 8 \ddagger \S$ & 0.03 \\
\hline Family size (>4 people) (\%) & 14.0 & 13.9 & $15 \cdot 4$ & $11 \cdot 1$ & $15 \cdot 8$ & 0.53 \\
\hline Smoking status (current smoker) (\%) & $14 \cdot 3$ & $11 \cdot 8$ & $15 \cdot 0$ & $16 \cdot 1$ & $15 \cdot 4$ & 0.28 \\
\hline Diabetes $(\%)$ & 1.1 & 2.5 & 2.9 & 4.3‡ & $3.6 \neq$ & 0.20 \\
\hline Home ownership (owner) (\%) & $57 \cdot 3$ & $58 \cdot 2$ & $55 \cdot 7$ & $57 \cdot 1$ & $62 \cdot 0$ & 0.58 \\
\hline Dietary supplement use (\%) & 11.8 & 12.5 & $15 \cdot 7$ & $10 \cdot 4$ & $8.6 \|$ & $0 \cdot 10$ \\
\hline Anti-psychotic medications (\%) & 3.9 & 3.9 & 3.9 & $2 \cdot 5$ & 3.9 & 0.85 \\
\hline Depression & 23.7 & 23.4 & $19 \cdot 9$ & $21 \cdot 0$ & $16 \cdot 6 \ddagger \S$ & 0.23 \\
\hline Anxiety & 11.7 & 8.8 & 7.7 & $8 \cdot 1$ & $6 \cdot 6 \ddagger$ & 0.28 \\
\hline Psychological distress & $19 \cdot 7$ & $17 \cdot 9$ & $15 \cdot 4$ & $17 \cdot 9$ & $12 \cdot 2 \ddagger \S$ & $0 \cdot 14$ \\
\hline \multicolumn{7}{|l|}{ Women } \\
\hline Age (years) & & & & & & $<0.001$ \\
\hline Mean & 33.9 & $34 \cdot 1$ & 35.4 & $35 \cdot 9 \ddagger \S$ & $36 \cdot 4 \ddagger \S$ & \\
\hline SD & $7 \cdot 0$ & $7 \cdot 2$ & $7 \cdot 6$ & $7 \cdot 1$ & $8 \cdot 0$ & \\
\hline BMI $\left(\mathrm{kg} / \mathrm{m}^{2}\right)$ & & & & & & 0.002 \\
\hline Mean & 23.9 & $24 \cdot 1$ & $24 \cdot 6$ & $24 \cdot 8$ & $25 \cdot 0 \ddagger \S$ & \\
\hline SD & 4.0 & $4 \cdot 1$ & 3.8 & 3.9 & $4 \cdot 1$ & \\
\hline Marital status (married) (\%) & 73.0 & 75.5 & 76.4 & $70 \cdot 0$ & $71 \cdot 7$ & 0.66 \\
\hline Education (university graduated) (\%) & 71.5 & $72 \cdot 4$ & $67 \cdot 9$ & $69 \cdot 3$ & $69 \cdot 3$ & 0.68 \\
\hline Physically active ( $\geq 1 \mathrm{~h} /$ week) (\%) & $5 \cdot 6$ & $6 \cdot 5$ & $6 \cdot 8$ & $7 \cdot 3$ & 8.5 & 0.66 \\
\hline Overweight or obese (\%) & $32 \cdot 2$ & $32 \cdot 7$ & $43 \cdot 7 \ddagger \S$ & $40 \cdot 0 \ddagger \S$ & $43 \cdot 7 \ddagger \S$ & 0.001 \\
\hline Family size (>4 people) (\%) & $13 \cdot 3$ & $11 \cdot 8$ & $12 \cdot 7$ & $10 \cdot 4$ & $13 \cdot 0$ & 0.78 \\
\hline Smoking status (current smoker) (\%) & 14.7 & $13 \cdot 8$ & 11.3 & $12 \cdot 1$ & $15 \cdot 8$ & 0.41 \\
\hline Diabetes (\%) & 0.3 & $2.0 \neq$ & $1 \cdot 1$ & $0.3 \S$ & 1.7 & 0.08 \\
\hline Home ownership (owner) (\%) & 57.9 & 56.9 & $56 \cdot 1$ & $63 \cdot 1$ & $65 \cdot 6 \S \|$ & 0.05 \\
\hline Dietary supplement use (\%) & 39.8 & 43.4 & $40 \cdot 3$ & $45 \cdot 6$ & 43.7 & 0.48 \\
\hline Anti-psychotic medications (\%) & 5.9 & 7.9 & 7.9 & $7 \cdot 9$ & $7 \cdot 6$ & 0.82 \\
\hline Depression & 39.1 & 39.8 & 33.7 & $30 \cdot 3 \neq \S$ & $28 \cdot 0 \pm \S$ & 0.002 \\
\hline Anxiety & $21 \cdot 1$ & $19 \cdot 8$ & 17.5 & $15 \cdot 2 \ddagger$ & $14 \cdot 1 \ddagger \S$ & 0.07 \\
\hline Psychological distress & 31.4 & 34.6 & $25 \cdot 1 \neq \S$ & $23.9 \pm \S$ & $20 \cdot 6 \neq \S$ & $<0.001$ \\
\hline
\end{tabular}

* Men: Q1: <277 mg/d, Q2: $277-<301 \mathrm{mg} / \mathrm{d}, \mathrm{Q3}: 301-<326 \mathrm{mg} / \mathrm{d}, \mathrm{Q} 4: 326-<358 \mathrm{mg} / \mathrm{d}, \mathrm{Q} 5:$ 2358 mg/d; women: Q1: <281 mg/d, Q2: $281-<303 \mathrm{mg} / \mathrm{d}, \mathrm{Q3}: 303-<325 \mathrm{mg} / \mathrm{d}$, Q4: $325-<356 \mathrm{mg} / \mathrm{d}, \mathrm{Q} 5: \geq 356 \mathrm{mg} / \mathrm{d}$.

† Obtained from ANOVA with Bonferroni correction or $x^{2}$ test, where appropriate.

¥ Significant compared with Q1.

§ Significant compared with Q2.

॥ Significant compared with Q3. 
Selected food groups and nutrient intakes of men and women across quintiles of energy-adjusted $\mathrm{Mg}$ intake are shown in Table 2. Men and women in the top quintile of $\mathrm{Mg}$ intake had greater intake of fruit, vegetables, legumes and nuts, whole grains, refined grains, dairy products, tea and coffee, protein, fibre, vitamins $\mathrm{B}_{2}, \mathrm{~B}_{3}, \mathrm{~B}_{5}, \mathrm{~B}_{6}$ and $\mathrm{B}_{12}$ compared with those in the bottom quintile. Among men, dietary intake of red meat, energy and vitamin $\mathrm{B}_{1}$ was different across quintiles of $\mathrm{Mg}$ intake. In addition, women were different in terms of dietary intake of red meat, energy, fat and carbohydrate across quintiles of dietary $\mathrm{Mg}$ intake.

Multivariable-adjusted OR for depression, anxiety and psychological distress across quintiles of dietary $\mathrm{Mg}$ intake in men are shown in Table 3. Compared with those in the bottom quintile, men in the top quintile of dietary $\mathrm{Mg}$ intake were less likely to be depressed (OR 0.64; 95\% CI 0.41, 0.97), anxious (OR 0.53; $95 \%$ CI 0.29, 0.98) and psychologically distressed (OR $0.56 ; 95 \%$ CI $0.35,0.89)$. These associations were significant even after controlling for demographic characteristics; however, taking dietary intakes of energy and relevant nutrients into account made these associations non-significant (depression; OR 0.77; $95 \%$ CI 0.47, 1.25, anxiety; OR 1.23; $95 \%$ CI 0.51, 3.00, psychological distress; OR 1.07; $95 \%$ CI 0.59, 1.94)). When we performed BMI-stratified analysis in men, a significant inverse association was found between dietary $\mathrm{Mg}$ intake and depression among normal-weight men (OR 0.41; $95 \%$ CI 0.21, 0.80), such that after adjusting for potential confounders men in the fifth quintile of $\mathrm{Mg}$ intake had a $55 \%$ lower risk of depression compared with those in the first quintile (OR 0.45; $95 \%$ CI 0.20, 0.99). Among overweight men, those in the top quintile of dietary $\mathrm{Mg}$ intake had lower odds of psychological distress compared with those in the lowest quintile (OR 0.44; 95\% CI $0 \cdot 22,0 \cdot 88)$; however, after controlling for dietary confounders, this association became non-significant (OR 1.15; $95 \%$ CI 0.48 , 2.73). No other significant association was found between $\mathrm{Mg}$ intake and psychiatric disorders either in normal-weight or overweight men. When men were categorised on the basis of EAR of $\mathrm{Mg}$, no significant association was found between deficient $\mathrm{Mg}$ intake and mental disorders either in the whole population or in BMI-stratified analysis.

Multivariable-adjusted OR for psychiatric disorders across quintiles of dietary $\mathrm{Mg}$ intake in women are shown in Table 4. Compared with those in the bottom quintile, women in the top quintile of dietary $\mathrm{Mg}$ intake were less likely to be depressed (OR 0.60; 95\% CI 0.43, 0.82), anxious (OR 0.61; 95\% CI 0.41, $0.90)$ and distressed (OR 0.56; $95 \%$ CI 0.40, 0.79). Such significant associations were also seen after controlling for potential confounders; however, when dietary intakes of energy and relevant nutrients were taken into account, these associations became non-significant (depression; OR 0.72; $95 \%$ CI 0.49, 1.06 and psychological distress; OR 0.74; 95\% CI 0.49, $1 \cdot 11$ ), except for anxiety, such that women in the fifth quintile of $\mathrm{Mg}$ intake were $39 \%$ less likely to be anxious compared with those in the first quintile (OR 0.61; 95\% CI 0.40, 0.93).

BMI-stratified analysis in women revealed no significant association between $\mathrm{Mg}$ intake and psychiatric disorders among normal-weight women. However, in overweight women, a significant inverse association was seen between dietary $\mathrm{Mg}$ intake and depression (OR 0.48; $95 \%$ CI 0.29, 0.80), such that in fully adjusted model women in the highest quintile of $\mathrm{Mg}$ intake had $55 \%$ lower odds of depression compared with those in the lowest quintile (OR 0.45; 95\% CI 0.24, 0.85). No other significant association was found between dietary intake of $\mathrm{Mg}$ and anxiety and psychological disorders in overweight women.

When we performed the analysis based on the cut-off points of EAR of $\mathrm{Mg}$ among women, we found a significant positive association between deficient $\mathrm{Mg}$ intake and anxiety either in crude (OR 1.60; $95 \%$ CI 1.12, 2.30) or adjusted models (OR 1.80; $95 \%$ CI $1 \cdot 19,2 \cdot 72)$. Such a finding was also seen among normalweight women (OR 1.73; $95 \%$ CI 1.01, 2.95). In addition, a significant positive association was found between deficient $\mathrm{Mg}$ intake and psychological distress among overweight women (OR 2.05; 95\% CI 1.18, 3.55); however, this association was non-significant when dietary variables were adjusted for.

\section{Discussion}

In this cross-sectional study, we found that higher dietary $\mathrm{Mg}$ intake was associated with lower odds of anxiety among women. Moreover, deficient Mg intake was positively associated with anxiety among all women and also normal-weight women. In addition, a significant inverse association was found between dietary $\mathrm{Mg}$ intake and depression among normalweight men and overweight women. To our knowledge, this is the first observational study assessing the association between dietary Mg intake and psychiatric disorders in the Middle East.

Depression and anxiety are among highly prevalent psychiatric disorders in the world ${ }^{(1,2)}$, which are associated with CVD, diabetes and cancers ${ }^{(37-40)}$. Although not life-threatening, they adversely affect the quality of life and life expectancy ${ }^{(3,4)}$. In the present study, we observed that higher $\mathrm{Mg}$ intake was related to a lower risk of depression among normal-weight men and overweight women. These findings were in line with a Spanish crosssectional study, in which an inverse association between $\mathrm{Mg}$ intake and depressive symptoms was reported among schoolchildren $^{(41)}$. Furthermore, data from a 20 -year prospective study suggested similar associations in middle-aged Finnish men ${ }^{(18)}$. In a meta-analysis, dietary intake of $\mathrm{Mg}$ was inversely associated with risk of depression ${ }^{(42)}$. Nevertheless, findings from a Spanish prospective study revealed no significant association between dietary $\mathrm{Mg}$ intake and risk of depression ${ }^{(19)}$. Such findings were also reported in Spanish university graduates ${ }^{(43)}$. In all mentioned studies, findings were not reported stratified by sex or BMI. Discrepant findings might be explained by various reasons. For instance, some confounding variables related to psychological characteristics, family factors and lifestyle have not been controlled for in other studies ${ }^{(43,44)}$.

In the present study, a significant inverse association was seen between dietary $\mathrm{Mg}$ intake and anxiety among women. Moreover, deficient Mg intake was positively associated with anxiety in all women and normal-weight women. In line with our findings, in a cross-sectional study, Sadeghi et al. ${ }^{(45)}$ reported that wholegrain consumption, known as a source of $\mathrm{Mg}$, was inversely associated with anxiety in women. In another similar study, adherence to dietary pattern rich in $\mathrm{Mg}$ was associated with 
Table 2. Selected food groups and nutrient intakes of men and women across quintiles (Q) of energy-adjusted magnesium intake* (Mean values with their standard errors)

\begin{tabular}{|c|c|c|c|c|c|c|c|c|c|c|c|}
\hline & \multicolumn{2}{|c|}{ Q1 } & \multicolumn{2}{|c|}{ Q2 } & \multicolumn{2}{|c|}{ Q3 } & \multicolumn{2}{|c|}{ Q4 } & \multicolumn{2}{|l|}{ Q5 } & \multirow[b]{2}{*}{$P+$} \\
\hline & Mean & SE & Mean & SE & Mean & SE & Mean & SE & Mean & SE & \\
\hline \multicolumn{12}{|l|}{ Men } \\
\hline \multicolumn{12}{|l|}{ Food groups (g/d) } \\
\hline Fruits & $156 \cdot 7$ & 8.6 & $227 \cdot 9 \ddagger$ & $9 \cdot 4$ & $282 \cdot 7 \ddagger \S$ & $11 \cdot 1$ & $303 \cdot 3 \neq \S$ & $12 \cdot 0$ & $367 \cdot 3 \neq \S \| \mid$ & $16 \cdot 6$ & $<0.001$ \\
\hline Vegetables & $150 \cdot 7$ & $4 \cdot 7$ & 197.3‡ & $4 \cdot 1$ & $232 \cdot 0 \ddagger \S$ & 4.4 & $261 \cdot 9 \ddagger \S \|$ & $5 \cdot 11$ & $308 \cdot 2 \ddagger \S \| \emptyset$ & $9 \cdot 6$ & $<0.001$ \\
\hline Red meat & $70 \cdot 6$ & $2 \cdot 7$ & 85.0‡ & $2 \cdot 8$ & $90.4 \ddagger$ & $2 \cdot 3$ & $84.8 \ddagger$ & $2 \cdot 1$ & $76.4 \|$ & $2 \cdot 5$ & $<0.001$ \\
\hline Fish & $7 \cdot 4$ & 0.81 & $10 \cdot 2$ & 0.74 & $12.0 \ddagger$ & 1.5 & $11 \cdot 1$ & 0.71 & $11 \cdot 3$ & 0.86 & 0.12 \\
\hline Legumes and nuts & 35.7 & 1.6 & $47 \cdot 6 \ddagger$ & 1.8 & $56.0 \ddagger$ & $1 \cdot 6$ & $64 \cdot 7 \ddagger \S$ & $2 \cdot 2$ & $69 \cdot 9 \ddagger \S \|$ & $3 \cdot 4$ & $<0.001$ \\
\hline Whole grains & $4 \cdot 7$ & $2 \cdot 0$ & $21.9 \ddagger$ & 1.9 & $29 \cdot 2 \ddagger$ & $2 \cdot 3$ & $48 \cdot 1 \neq \S$ & 3.6 & $109 \cdot 8 \mp \S \| \emptyset$ & $7 \cdot 3$ & $<0.001$ \\
\hline Refined grains & $513 \cdot 6$ & $12 \cdot 7$ & $440 \cdot 7 \ddagger$ & $9 \cdot 4$ & $393.9 \neq \S$ & $7 \cdot 3$ & $353 \cdot 2 \ddagger \S \|$ & 6.9 & $284 \cdot 0 \mp \S \| \emptyset$ & $7 \cdot 5$ & $<0.001$ \\
\hline Dairy products & $205 \cdot 6$ & $9 \cdot 3$ & $282.4 \ddagger$ & $10 \cdot 3$ & $323.1 \mp$ & $11 \cdot 1$ & $379 \cdot 9 \neq \S$ & $15 \cdot 5$ & $509 \cdot 7 \ddagger \S \| \emptyset$ & $24 \cdot 6$ & $<0.001$ \\
\hline Tea and coffee & $330 \cdot 3$ & $17 \cdot 4$ & 367.9 & $16 \cdot 3$ & 392.7 & $17 \cdot 0$ & $467 \cdot 3 \ddagger \S$ & $19 \cdot 8$ & $476 \cdot 4 \ddagger \S \|$ & $22 \cdot 3$ & $<0.001$ \\
\hline \multicolumn{12}{|l|}{ Nutrients } \\
\hline Energy (kJ/d) & $11892 \cdot 6$ & 194.9 & 10021.9‡ & $208 \cdot 3$ & $9141.6 \neq \S$ & $189 \cdot 5$ & 9533.6‡ & $213 \cdot 3$ & $11278 \cdot 8 \S \| \mid$ & $195 \cdot 3$ & $<0.001$ \\
\hline Protein $(g / d)$ & 85.4 & 1.00 & 88.3 & 0.81 & $90 \cdot 7 \ddagger$ & 0.78 & $92 \cdot 3 \neq \S$ & 0.75 & $94 \cdot 2 \ddagger \S \|$ & 0.85 & $<0.001$ \\
\hline Fat $(g / d)$ & $97 \cdot 8$ & 1.6 & $100 \cdot 1$ & $1 \cdot 1$ & $101 \cdot 4$ & 0.99 & 101.4 & 0.92 & $97 \cdot 2$ & $1 \cdot 1$ & 0.02 \\
\hline Carbohydrate $(\mathrm{g} / \mathrm{d})$ & $292 \cdot 1$ & $4 \cdot 1$ & $287 \cdot 9$ & 3.0 & $284 \cdot 6$ & $2 \cdot 7$ & $284 \cdot 3$ & $2 \cdot 5$ & 295.8 & 3.0 & 0.04 \\
\hline Dietary fibre $(\mathrm{g} / \mathrm{d})$ & $17 \cdot 1$ & 0.2 & $20.0 \ddagger$ & 0.2 & $22 \cdot 0 \ddagger \S$ & 0.2 & $23 \cdot 5 \ddagger \S \|$ & 0.2 & $26 \cdot 4 \ddagger \S \|$ & 0.3 & $<0.001$ \\
\hline Vitamin $B_{1}(\mathrm{mg} / \mathrm{d})$ & $2 \cdot 0$ & 0.05 & 1.8 & 0.03 & $1.7 \ddagger$ & 0.02 & $1.7 \ddagger$ & 0.02 & $1.8 \ddagger$ & 0.02 & $<0.001$ \\
\hline Vitamin $B_{6}(\mathrm{mg} / \mathrm{d})$ & 1.6 & 0.02 & $1.8 \ddagger$ & 0.02 & $2.0 \ddagger \S$ & 0.01 & $2 \cdot 1 \ddagger \S$ & 0.01 & $2 \cdot 2 \ddagger \S \| \emptyset$ & 0.02 & $<0.001$ \\
\hline Folate $(\mu \mathrm{g} / \mathrm{d})$ & $802 \cdot 2$ & $17 \cdot 2$ & $759 \cdot 6$ & $12 \cdot 6$ & $733.5 \ddagger$ & $9 \cdot 5$ & $733.0 \ddagger$ & 9.9 & $761 \cdot 2$ & $10 \cdot 8$ & $<0.001$ \\
\hline Vitamin $\mathrm{B}_{2}(\mathrm{mg} / \mathrm{d})$ & 1.6 & 0.02 & $1 \cdot 7 \ddagger$ & 0.01 & $1.8 \ddagger$ & 0.01 & $1.9 \ddagger \S$ & 0.02 & $2 \cdot 1 \ddagger \S \| \emptyset$ & 0.03 & $<0.001$ \\
\hline Vitamin $B_{3}(\mathrm{mg} / \mathrm{d})$ & $26 \cdot 8$ & 0.3 & 25.9 & 0.2 & $25 \cdot 2 \ddagger$ & 0.2 & $24 \cdot 6 \ddagger \S$ & 0.2 & $24 \cdot 2 \ddagger \S \|$ & 0.2 & $<0.001$ \\
\hline Vitamin $B_{5}(\mathrm{mg} / \mathrm{d})$ & $5 \cdot 7$ & 0.04 & $5 \cdot 9 \ddagger$ & 0.03 & $6 \cdot 1 \ddagger \S$ & 0.03 & $6 \cdot 3 \ddagger \S \|$ & 0.04 & $6 \cdot 7 \ddagger \S \| \Upsilon$ & 0.06 & $<0.001$ \\
\hline $\mathrm{Fe}(\mathrm{mg} / \mathrm{d})$ & $18 \cdot 4$ & 0.2 & $18 \cdot 0$ & 0.2 & $17 \cdot 6 \ddagger$ & $0 \cdot 1$ & $17 \cdot 5 \ddagger$ & 0.1 & $17 \cdot 6$ & $0 \cdot 1$ & 0.01 \\
\hline$n$-3 Fatty acids $(\mathrm{g} / \mathrm{d})$ & $1 \cdot 7$ & 0.05 & $1 \cdot 7$ & 0.03 & $1 \cdot 7$ & 0.04 & $1 \cdot 7$ & 0.02 & 1.6 & 0.03 & 0.23 \\
\hline Vitamin D $(\mathrm{mg} / \mathrm{d})$ & 39.9 & 1.6 & 39.5 & $1 \cdot 2$ & $38 \cdot 2$ & $1 \cdot 2$ & $40 \cdot 2$ & $1 \cdot 2$ & 35.4 & $1 \cdot 2$ & 0.07 \\
\hline Vitamin $B_{12}(\mu \mathrm{g} / \mathrm{d})$ & 2.5 & 0.06 & $2 \cdot 8$ & 0.05 & $3.0 \ddagger$ & 0.04 & $3 \cdot 1 \neq \S$ & 0.05 & $3 \cdot 3 \ddagger \S ॥$ & 0.07 & $<0.001$ \\
\hline \multicolumn{12}{|l|}{ Women } \\
\hline \multicolumn{12}{|l|}{ Food groups (g/d) } \\
\hline Fruits & $236 \cdot 9$ & $10 \cdot 6$ & $301 \cdot 2 \ddagger$ & $9 \cdot 3$ & $348 \cdot 1 \neq \S$ & $9 \cdot 8$ & $405 \cdot 5 \ddagger \S \|$ & $12 \cdot 3$ & $459 \cdot 8 \mp \S \| \emptyset$ & $15 \cdot 5$ & $<0.001$ \\
\hline Vegetables & $174 \cdot 7$ & 4.5 & $211.4 \ddagger$ & 3.5 & $239 \cdot 6 \neq \S$ & 4.5 & $283 \cdot 7 \ddagger \S \|$ & $5 \cdot 7$ & $320 \cdot 0 \mp \S \| \emptyset$ & 8.9 & $<0.001$ \\
\hline Red meat & $72 \cdot 8$ & $2 \cdot 6$ & 82.9‡ & $1 \cdot 8$ & $79 \cdot 4$ & 1.6 & $79 \cdot 3$ & 1.6 & $72 \cdot 3 \S$ & $2 \cdot 1$ & $<0.001$ \\
\hline Fish & $7 \cdot 8$ & 0.5 & $9 \cdot 3$ & 0.6 & $10 \cdot 5 \ddagger$ & 0.5 & $12 \cdot 2 \ddagger \S$ & 0.6 & $10.9 \ddagger$ & 0.6 & $<0.001$ \\
\hline Legumes and nuts & 35.9 & $1 \cdot 3$ & 48.0‡ & $1 \cdot 3$ & $49 \cdot 2 \ddagger$ & $1 \cdot 2$ & $55 \cdot 2 \ddagger \S$ & 1.4 & $63 \cdot 8 \ddagger \S \| \Upsilon$ & $2 \cdot 2$ & $<0.001$ \\
\hline Whole grains & $7 \cdot 1$ & 1.6 & $22.0 \ddagger$ & 1.5 & $36.0 \ddagger$ & 2.5 & $49 \cdot 4 \ddagger \S$ & $3 \cdot 1$ & $100 \cdot 6 \neq \S \| \emptyset$ & $6 \cdot 3$ & $<0.001$ \\
\hline Refined grains & $484 \cdot 0$ & $11 \cdot 1$ & $428.9 \ddagger$ & $6 \cdot 8$ & $392.9 \neq \S$ & 5.9 & $350 \cdot 4 \ddagger \S \|$ & $5 \cdot 7$ & $278 \cdot 1 \neq \S \| \mathbb{\|}$ & $6 \cdot 9$ & $<0.001$ \\
\hline Dairy products & $238 \cdot 3$ & 9.7 & 295.3‡ & $9 \cdot 7$ & $339.0 \ddagger$ & $10 \cdot 8$ & 394.3†§॥ & $13 \cdot 0$ & $482.9 \ddagger \S \| \mid$ & $17 \cdot 8$ & $<0.001$ \\
\hline Tea and coffee & $322 \cdot 7$ & $12 \cdot 2$ & $329 \cdot 1$ & $11 \cdot 8$ & 360.5 & $13 \cdot 7$ & $392 \cdot 6 \ddagger \S$ & 14.5 & $394.6 \neq \S$ & $16 \cdot 1$ & $<0.001$ \\
\hline \multicolumn{12}{|l|}{ Nutrients } \\
\hline Energy (kJ/d) & $11288 \cdot 4$ & $175 \cdot 7$ & $9069 \cdot 6 \ddagger$ & 174.4 & $8413 \cdot 1 \ddagger$ & $164 \cdot 0$ & $8887 \cdot 2 \ddagger$ & $160 \cdot 6$ & $10759 \cdot 1 \S \|$ & $172 \cdot 3$ & $<0.001$ \\
\hline Protein $(g / d)$ & $80 \cdot 0$ & 0.8 & $86.6 \ddagger$ & 0.5 & $88.5 \ddagger$ & 0.5 & $90 \cdot 1 \neq \S$ & 0.6 & $91.4 \mp \S \|$ & $7 \cdot 0$ & $<0.001$ \\
\hline Fat $(g / d)$ & $98 \cdot 7$ & $1 \cdot 1$ & $100 \cdot 0$ & 0.8 & 98.7 & 0.7 & 99.3 & $0 \cdot 7$ & 95.7§】 & 0.9 & 0.009 \\
\hline Carbohydrate $(\mathrm{g} / \mathrm{d})$ & $298 \cdot 2$ & $2 \cdot 8$ & 291.5 & $2 \cdot 1$ & $294 \cdot 1$ & 1.9 & $293 \cdot 3$ & $2 \cdot 0$ & $303.6 \S \|$ | & 2.6 & 0.002 \\
\hline Dietary fibre $(\mathrm{g} / \mathrm{d})$ & $17 \cdot 9$ & 0.2 & $21 \cdot 2 \ddagger$ & $0 \cdot 1$ & $22 \cdot 9 \neq \S$ & $0 \cdot 2$ & $24 \cdot 7 \ddagger \S \|$ & 0.2 & $28 \cdot 1 \neq \S \| \mid$ & 0.3 & $<0.001$ \\
\hline Vitamin $B_{1}(\mathrm{mg} / \mathrm{d})$ & $1 \cdot 8$ & 0.03 & $1 \cdot 8$ & 0.02 & 1.8 & 0.02 & 1.7 & 0.01 & 1.8 & 0.02 & 0.49 \\
\hline Vitamin $B_{6}(\mathrm{mg} / \mathrm{d})$ & 1.6 & 0.02 & $1.9 \ddagger$ & 0.01 & $1.9 \neq \S$ & 0.01 & $2 \cdot 0 \ddagger \S \|$ & 0.01 & $2 \cdot 2 \ddagger \S \| \emptyset$ & 0.02 & $<0.001$ \\
\hline Folate $(\mu \mathrm{g} / \mathrm{d})$ & $756 \cdot 3$ & $13 \cdot 2$ & $746 \cdot 2$ & 8.5 & $742 \cdot 1$ & $7 \cdot 7$ & 729.9 & $7 \cdot 2$ & 755.0 & 9.5 & 0.27 \\
\hline Vitamin $\mathrm{B}_{2}(\mathrm{mg} / \mathrm{d})$ & 1.5 & 0.02 & $1.7 \ddagger$ & 0.01 & $1 \cdot 8 \mp \S$ & 0.01 & $1 \cdot 9 \ddagger \S \|$ & 0.01 & $2 \cdot 1 \neq \S \| \emptyset$ & 0.02 & $<0.001$ \\
\hline Vitamin $B_{3}(\mathrm{mg} / \mathrm{d})$ & $25 \cdot 4$ & 0.2 & $25 \cdot 2$ & $0 \cdot 1$ & $25 \cdot 0$ & $0 \cdot 1$ & $24 \cdot 3 \ddagger \S$ & 0.1 & $23 \cdot 9 \ddagger \S \|$ & $0 \cdot 2$ & $<0.001$ \\
\hline Vitamin $B_{5}(\mathrm{mg} / \mathrm{d})$ & $5 \cdot 6$ & 0.04 & $6 \cdot 0 \ddagger$ & 0.03 & $6 \cdot 1 \mp \S$ & 0.03 & $6 \cdot 4 \ddagger \S \|$ & 0.03 & $6 \cdot 7 \ddagger \S \| \Upsilon$ & 0.04 & $<0.001$ \\
\hline $\mathrm{Fe}(\mathrm{mg} / \mathrm{d})$ & $17 \cdot 3$ & 0.2 & $17 \cdot 7$ & $0 \cdot 1$ & $17 \cdot 5$ & $0 \cdot 1$ & $17 \cdot 1$ & $0 \cdot 1$ & $17 \cdot 4$ & $0 \cdot 1$ & $0 \cdot 20$ \\
\hline$n$-3 Fatty acids $(\mathrm{g} / \mathrm{d})$ & 1.6 & 0.04 & $1 \cdot 7$ & 0.03 & 1.7 & 0.03 & $1.8 \neq \S$ & 0.04 & 1.7 & 0.04 & 0.001 \\
\hline Vitamin D $(\mathrm{mg} / \mathrm{d})$ & 34.9 & 1.2 & $36 \cdot 2$ & 0.9 & $36 \cdot 1$ & 1.0 & 34.8 & 0.9 & 33.6 & $1 \cdot 3$ & 0.46 \\
\hline Vitamin $B_{12}(\mu \mathrm{g} / \mathrm{d})$ & $2 \cdot 5$ & 0.05 & $2 \cdot 8 \ddagger$ & 0.04 & $2 \cdot 9 \ddagger$ & 0.04 & $3 \cdot 0 \neq \S$ & 0.04 & $3 \cdot 1 \mp \S \|$ & 0.06 & $<0.001$ \\
\hline
\end{tabular}

* All food groups and nutrients are energy adjusted. Mg quintiles for men: Q1: <277 mg/d, Q2: 277-<301 mg/d, Q3: $301-<326 \mathrm{mg} / \mathrm{d}, \mathrm{Q} 4:$ 326-<358 mg/d, Q5: $\geq 358 \mathrm{mg} / \mathrm{d}$; Mg quintiles for women: Q1: <281 mg/d, Q2: $281-<303 \mathrm{mg} / \mathrm{d}, \mathrm{Q} 3: 303-<325 \mathrm{mg} / \mathrm{d}, \mathrm{Q} 4: 325-<356 \mathrm{mg} / \mathrm{d}, \mathrm{Q} 5: \geq 356 \mathrm{mg} / \mathrm{d}$.

$\dagger$ Obtained from ANOVA with Bonferroni correction.

‡ Significant compared with Q1.

§ Significant compared with Q2.

II Significant compared with Q3.

II Significant compared with Q4

decreased odds of anxiety in females ${ }^{(46)}$. Boyle et al. ${ }^{(47)}$ reported that $\mathrm{Mg}$ supplementation among anxious individuals had beneficial effects on symptoms. In addition, findings from a systematic review introduced $\mathrm{Mg}$ supplementation as an effective modality for treating anxiety and anxiety-related conditions ${ }^{(48)}$. However, some studies did not reach a significant correlation ${ }^{(17,20)}$. 
Table 3. Psychiatric disorders based on quintiles (Q) of energy-adjusted magnesium intake and estimate average requirement (EAR) among men (Odds ratios and $95 \%$ confidence intervals)

\begin{tabular}{|c|c|c|c|c|c|c|c|c|c|c|c|c|c|}
\hline & \multicolumn{10}{|c|}{ Quintiles of energy-adjusted Mg intake* } & \multicolumn{3}{|c|}{ Based on EAR† } \\
\hline & \multirow[b]{2}{*}{ Q1 } & \multicolumn{2}{|r|}{ Q2 } & \multicolumn{2}{|r|}{ Q3 } & \multicolumn{2}{|r|}{ Q4 } & \multicolumn{2}{|r|}{ Q5 } & \multirow[b]{2}{*}{$P_{\text {trend }}$} & \multirow[b]{2}{*}{ Normal intake } & \multicolumn{2}{|c|}{ Under EAR } \\
\hline & & OR & $95 \% \mathrm{Cl}$ & OR & $95 \% \mathrm{Cl}$ & OR & $95 \% \mathrm{Cl}$ & OR & $95 \% \mathrm{Cl}$ & & & OR & $95 \% \mathrm{Cl}$ \\
\hline \multicolumn{14}{|c|}{ Total } \\
\hline \multicolumn{14}{|c|}{ Depression $\ddagger$} \\
\hline Crude & 1 & 0.98 & $0.66,1.46$ & 0.79 & $0.53,1.19$ & $0 \cdot 85$ & $0.56,1.27$ & 0.64 & $0.41,0.97$ & 0.03 & 1 & 1.33 & $0.96,1.83$ \\
\hline Model 1 & 1 & 0.99 & $0.66,1.48$ & 0.78 & $0.51,1.18$ & 0.84 & $0.56,1.27$ & 0.62 & $0.40,0.95$ & 0.02 & 1 & 1.38 & $0.99,1.91$ \\
\hline Model 2 & 1 & 1.09 & $0.72,1.64$ & 0.89 & $0.58,1.39$ & 1.00 & $0.64,1.55$ & 0.77 & $0.47,1.25$ & 0.30 & 1 & 1.23 & $0.86,1.77$ \\
\hline \multicolumn{14}{|l|}{ Anxiety§ } \\
\hline Crude & 1 & 0.72 & $0.41,1.27$ & 0.63 & $0.35,1.12$ & 0.66 & $0.37,1.17$ & 0.53 & $0.29,0.98$ & 0.04 & 1 & 1.15 & $0.58,2.27$ \\
\hline Model 1 & 1 & 0.73 & $0.41,1.30$ & 0.61 & $0.33,1.10$ & 0.68 & $0.38,1.23$ & 0.52 & $0.28,0.97$ & 0.04 & 1 & 1.19 & $0.59,2.37$ \\
\hline Model 2 & 1 & 1.01 & $0.54,1.90$ & 1.00 & $0.49,2.04$ & $1 \cdot 30$ & $0.60,2.78$ & $1 \cdot 23$ & $0.51,3.00$ & 0.50 & 1 & 0.82 & $0.34,1.96$ \\
\hline \multicolumn{14}{|c|}{ Psychological distress\|l } \\
\hline Crude & 1 & $0 \cdot 88$ & $0.57,1.35$ & 0.73 & $0.47,1.14$ & 0.88 & $0.57,1.35$ & 0.56 & $0.35,0.89$ & 0.03 & 1 & $1 \cdot 24$ & $0.88,1.75$ \\
\hline Model 1 & 1 & 0.88 & $0.57,1.35$ & 0.73 & $0.47,1.14$ & 0.91 & $0.59,1.39$ & 0.55 & $0.34,0.89$ & 0.03 & 1 & 1.27 & $0.89,1.80$ \\
\hline Model 2 & 1 & 1.22 & $0.77,1.95$ & 1.22 & $0.72,2.04$ & 1.62 & $0.96,2.74$ & 1.07 & $0.59,1.94$ & 0.48 & 1 & 0.96 & $0.64,1.43$ \\
\hline \multicolumn{14}{|c|}{$\mathrm{BMl}<25 \mathrm{~kg} / \mathrm{m}^{2}$} \\
\hline \multicolumn{14}{|c|}{ Depression } \\
\hline Crude & 1 & 0.59 & $0.32,1 \cdot 10$ & 0.67 & $0.36,1 \cdot 22$ & 0.59 & $0.32,1 \cdot 10$ & 0.41 & $0.21,0.80$ & 0.01 & 1 & 1.76 & $0.98,3.17$ \\
\hline Model 1 & 1 & 0.59 & $0.31,1.11$ & 0.67 & $0.36,1.32$ & 0.57 & $0.30,1.07$ & 0.35 & $0.17,0.70$ & 0.005 & 1 & 2.07 & $1 \cdot 12,3.82$ \\
\hline Model 2 & 1 & 0.64 & $0.33,1.23$ & 0.73 & $0.38,1.43$ & 0.65 & $0.32,1.31$ & 0.45 & $0.20,0.99$ & 0.08 & 1 & 1.68 & $0 \cdot 87,3 \cdot 26$ \\
\hline \multicolumn{14}{|l|}{ Anxiety } \\
\hline Crude & 1 & 0.61 & $0.25,1.49$ & 0.54 & $0.21,1.35$ & 0.61 & $0.25,1.49$ & 0.40 & $0.15,1 \cdot 10$ & 0.09 & 1 & 2.03 & $4.60,8.92$ \\
\hline Model 1 & 1 & 0.63 & $0.25,1.54$ & 0.54 & $0.21,1.39$ & 0.65 & $0.26,1.60$ & 0.35 & $0.12,0.99$ & 0.06 & 1 & $3 \cdot 30$ & $0.66,16 \cdot 3$ \\
\hline Model 2 & 1 & 0.99 & $0.36,2.73$ & 1.05 & $0.33,3.27$ & 1.52 & $0.45,5.13$ & 1.07 & $0.23,4.89$ & 0.67 & 1 & 1.05 & $0.15,7.25$ \\
\hline \multicolumn{14}{|c|}{ Psychological distress } \\
\hline Crude & 1 & 0.66 & $0.34,1.29$ & 0.80 & $0.42,1.53$ & 0.70 & $0.36,1.36$ & 0.50 & $0.24,1.02$ & 0.10 & 1 & 1.50 & $0.81,2.75$ \\
\hline Model 1 & 1 & 0.67 & $0.34,1.31$ & 0.81 & $0.42,1.56$ & 0.74 & $0.38,1.43$ & 0.47 & $0.23,0.98$ & 0.09 & 1 & 1.61 & $0.86,2.98$ \\
\hline Model 2 & 1 & 0.81 & $0.39,1.66$ & $1 \cdot 11$ & $0.39,1.66$ & 1.06 & $0.47,2 \cdot 36$ & 0.76 & $0.29,1.98$ & 0.88 & 1 & $1 \cdot 24$ & $0.61,2.51$ \\
\hline \multicolumn{14}{|c|}{$\mathrm{BMI} \geq 25 \mathrm{~kg} / \mathrm{m}^{2}$} \\
\hline \multicolumn{14}{|c|}{ Depression } \\
\hline Crude & 1 & 1.37 & $0 \cdot 78,2 \cdot 40$ & 1.00 & $0.55,1.80$ & $1 \cdot 20$ & $0 \cdot 68,2 \cdot 13$ & 0.87 & $0.48,1.59$ & 0.56 & 1 & $1 \cdot 16$ & $0.76,1 \cdot 77$ \\
\hline Model 1 & 1 & 1.36 & $0.77,2.40$ & 0.94 & $0.52,1.73$ & 1.23 & $0.69,2 \cdot 21$ & 0.92 & $0.50,1.68$ & 0.68 & 1 & 1.13 & $0.74,1.73$ \\
\hline \multirow{2}{*}{\multicolumn{14}{|c|}{ Anxiety }} \\
\hline & & & & & & & & & & & & & \\
\hline Crude & 1 & 0.72 & $0.32,1.58$ & 0.82 & $0.38,1.78$ & 0.73 & $0.33,1.62$ & 0.47 & $0.19,1.13$ & 0.13 & 1 & 1.09 & $0.43,2.81$ \\
\hline Model 1 & 1 & 0.70 & $0.31,1.57$ & 0.77 & $0.34,1.71$ & 0.77 & $0.34,1.72$ & 0.51 & $0.20,1.25$ & 0.22 & 1 & 1.01 & $0.39,2.61$ \\
\hline Model 2 & 1 & 0.87 & $0 \cdot 35,2 \cdot 12$ & $1 \cdot 15$ & $0.44,3.03$ & $1 \cdot 31$ & $0.46,3.76$ & $1 \cdot 12$ & $0.32,3.96$ & 0.59 & 1 & 0.89 & $0.27,2.90$ \\
\hline Psychologic & & & & & & & & & & & & & \\
\hline Crude & 1 & 0.82 & $0.45,1.50$ & 0.66 & $0.35,1.24$ & 1.08 & $0.60,1.92$ & 0.44 & $0.22,0.88$ & 0.11 & 1 & 1.22 & $0.76,1.95$ \\
\hline Model 1 & 1 & 0.80 & $0.43,1.48$ & 0.60 & $0.31,1.14$ & $1 \cdot 12$ & $0.62,2.02$ & 0.46 & $0.23,0.93$ & $0 \cdot 16$ & 1 & $1 \cdot 18$ & $0.73,1.90$ \\
\hline Model 2 & 1 & 1.34 & $0.68,2.66$ & 1.24 & $0.58,2.66$ & $2 \cdot 52$ & $1.21,5.23$ & $1 \cdot 15$ & $0.48,2.73$ & 0.22 & 1 & 0.82 & $0.48,1.39$ \\
\hline
\end{tabular}

* All men: Q1: $<277 \mathrm{mg} / \mathrm{d}$, Q2: 277-<301 mg/d, Q3: $301-<326 \mathrm{mg} / \mathrm{d}$, Q4: $326-<358 \mathrm{mg} / \mathrm{d}, \quad \mathrm{Q} 5: \geq 358 \mathrm{mg} / \mathrm{d} ; \quad \mathrm{BMl}<25 \mathrm{~kg} / \mathrm{m}^{2}: \quad \mathrm{Q} 1:<274 \mathrm{mg} / \mathrm{d}, \quad \mathrm{Q} 2: 274-<297 \mathrm{mg} / \mathrm{d}$, Q3: $297-<319 \mathrm{mg} / \mathrm{d}, \mathrm{Q} 4: 319-<349 \mathrm{mg} / \mathrm{d}, \mathrm{Q} 5: \geq 349 \mathrm{mg} / \mathrm{d}$; BMl $\geq 25 \mathrm{~kg} / \mathrm{m}^{2}:$ Q1: $<279 \mathrm{mg} / \mathrm{d}, \mathrm{Q} 2: 279-<304 \mathrm{mg} / \mathrm{d}, \mathrm{Q} 3: 304-<328 \mathrm{mg} / \mathrm{d}, \mathrm{Q} 4: 328-<363 \mathrm{mg} / \mathrm{d}, \mathrm{Q} 5: \geq 363 \mathrm{mg} / \mathrm{d}$. † EAR; men: $350 \mathrm{mg} / \mathrm{d}$

† Depression: model 1: adjusted for education, smoking status and anti-psychotic medications, and model 2: additionally adjusted for dietary intake of energy, fat, carbohydrate and vitamin $B_{2}$.

$\S$ Anxiety: model 1: adjusted for smoking status, anti-psychotic medications and supplements use, and model 2: additionally adjusted for dietary intake of energy, fibre, vitamin $B_{1}$ and vitamin $B_{2}$.

II Psychological distress: model 1: adjusted for anti-psychotic medications, and model 2: additionally adjusted for dietary intake of energy, fibre and vitamin $\mathrm{B}_{6}$.

For instance, a clinical trial concluded that $\mathrm{Mg}$ and zinc supplementation did not reduce postpartum anxiety and depressive symptoms among women ${ }^{(17)}$. Furthermore, an Italian study failed to find any association between total plasma $\mathrm{Mg}$ levels and anxiety among patients with major depressive disorders ${ }^{(20)}$. Different findings on the association between $\mathrm{Mg}$ intake and anxiety might be explained by adjusting for confounders, particularly dietary intakes. As seen in the current study, some associations between $\mathrm{Mg}$ intake and psychiatric disorders became nonsignificant after considering other dietary intakes as covariates. However, in some previous studies, potential confounders such as dietary variables were not considered on the association between $\mathrm{Mg}$ intake and psychiatric disorders ${ }^{(17,20)}$.
The sex disparity on the association between dietary Mg intake and psychiatric disorders could be explained by the differential influence of gonadal steroids on $\operatorname{mood}^{(49,50)}$. In addition, the accuracy of dietary assessment might be different between men and women. Previous studies have indicated that actual food choices ${ }^{(51)}$, self-reported preferences for foods ${ }^{(52)}$ and accuracy of reported dietary intakes ${ }^{(53)}$ are different between men and women.

In the current study, we observed different findings among normal-weight and overweight participants. Different $\mathrm{Mg}$ requirement in overweight participants compared with normalweight ones might be a reason for this. In addition, hormonal imbalance in obese individuals compared with normal-weight ones might also explain the different associations ${ }^{(54)}$. Furthermore, 
Table 4. Psychiatric disorders based on quintiles $(Q)$ of energy-adjusted magnesium intake and estimated average requirement (EAR) among women (Odds ratios and $95 \%$ confidence intervals)

\begin{tabular}{|c|c|c|c|c|c|c|c|c|c|c|c|c|c|}
\hline & \multicolumn{10}{|c|}{ Quintiles of energy-adjusted Mg intake* } & \multicolumn{3}{|c|}{ Based on EAR $\dagger$} \\
\hline & \multirow[b]{2}{*}{ Q1 } & \multicolumn{2}{|r|}{ Q2 } & \multicolumn{2}{|r|}{ Q3 } & \multicolumn{2}{|r|}{ Q4 } & \multicolumn{2}{|r|}{ Q5 } & \multirow[b]{2}{*}{$P_{\text {trend }}$} & \multirow[b]{2}{*}{ Normal intake } & \multicolumn{2}{|c|}{ Under EAR } \\
\hline & & OR & $95 \% \mathrm{Cl}$ & OR & $95 \% \mathrm{Cl}$ & OR & $95 \% \mathrm{Cl}$ & OR & $95 \% \mathrm{Cl}$ & & & OR & $95 \% \mathrm{Cl}$ \\
\hline \multicolumn{14}{|c|}{ Total } \\
\hline \multicolumn{14}{|c|}{ Depression $\ddagger$} \\
\hline Crude & 1 & 1.02 & $0.75,1.39$ & 0.79 & $0.58,1.07$ & 0.67 & $0.49,0.92$ & 0.60 & $0.43,0.82$ & $<0.001$ & 1 & 1.23 & $0.90,1.69$ \\
\hline Model 1 & 1 & 1.06 & $0.76,1.48$ & 0.80 & $0.57,1.12$ & 0.68 & $0.48,0.95$ & 0.59 & $0.41,0.83$ & $<0.001$ & 1 & 1.15 & $0.81,1.63$ \\
\hline Model 2 & 1 & 1.08 & $0.76,1.53$ & 0.83 & $0.58,1.19$ & 0.74 & $0.51,1.08$ & 0.72 & $0.49,1.06$ & 0.01 & 1 & 0.98 & $0.66,1.44$ \\
\hline \multicolumn{14}{|l|}{ Anxiety§ } \\
\hline Crude & 1 & 0.92 & $0.64,1.33$ & $0 \cdot 79$ & $0.54,1.15$ & 0.67 & $0.45,0.98$ & 0.61 & $0.41,0.90$ & 0.004 & 1 & $1 \cdot 60$ & $1 \cdot 12,2 \cdot 30$ \\
\hline Model 1 & 1 & 0.90 & $0.61,1.32$ & 0.75 & $0.50,1.12$ & 0.65 & $0.43,0.99$ & 0.61 & $0.40,0.93$ & 0.006 & 1 & 1.59 & $1.08,2 \cdot 33$ \\
\hline Model 2 & 1 & 0.81 & $0.54,1.21$ & 0.66 & $0.43,1.01$ & 0.61 & $0.39,0.94$ & 0.61 & $0.40,0.93$ & 0.009 & 1 & 1.80 & $1 \cdot 19,2 \cdot 72$ \\
\hline \multicolumn{14}{|c|}{ Psychological distress\|l } \\
\hline Crude & 1 & 1.16 & $0.84,1.58$ & 0.73 & $0.52,1.01$ & 0.68 & $0.49,0.96$ & 0.56 & $0.40,0.79$ & $<0.001$ & 1 & 1.38 & $0.99,1.91$ \\
\hline Model 1 & 1 & 1.14 & $0.83,1.56$ & 0.69 & $0.50,0.97$ & 0.65 & $0.47,0.92$ & 0.54 & $0.38,0.76$ & $<0.001$ & 1 & 1.40 & $1.01,1.96$ \\
\hline Model 2 & 1 & 1.31 & $0.93,1.84$ & 0.84 & $0.58,1.22$ & 0.85 & $0.58,1.25$ & 0.74 & $0.49,1.11$ & 0.01 & 1 & 0.99 & $0.67,1.46$ \\
\hline \multicolumn{14}{|c|}{$\mathrm{BMl}<25 \mathrm{~kg} / \mathrm{m}^{2}$} \\
\hline \multicolumn{14}{|l|}{ Depression } \\
\hline Crude & 1 & $1 \cdot 10$ & $0.73,1.65$ & 1.05 & $0.70,1.57$ & 0.67 & $0.44,1.03$ & 0.60 & $0.39,0.93$ & 0.003 & 1 & 1.14 & $0.76,1.71$ \\
\hline Model 1 & 1 & 1.38 & $0.88,2 \cdot 16$ & $1 \cdot 11$ & $0.71,1.73$ & 0.78 & $0.49,1.24$ & 0.71 & $0.44,1 \cdot 15$ & 0.02 & 1 & 0.92 & $0.58,1.44$ \\
\hline Model 2 & 1 & 1.40 & $0.88,2.24$ & 1.15 & $0.71,1.87$ & 0.83 & $0.50,1.39$ & 0.84 & $0.50,1.42$ & 0.12 & 1 & 0.79 & $0.47,1.32$ \\
\hline \multicolumn{14}{|l|}{ Anxiety } \\
\hline Crude & 1 & 0.84 & $0.51,1.38$ & 0.76 & $0.46,1.27$ & 0.57 & $0.33,0.99$ & 0.50 & $0.28,0.87$ & 0.005 & 1 & 1.79 & $1.12,2.84$ \\
\hline Model 1 & & 0.91 & $0.54,1.55$ & 0.66 & $0.38,1.14$ & 0.65 & $0.36,1.15$ & 0.61 & $0.34,1.09$ & 0.04 & 1 & 1.55 & $0.94,2.5$ \\
\hline Model 2 & 1 & 0.84 & $0.48,1.45$ & 0.60 & $0.33,1.07$ & 0.61 & $0.33,1.11$ & 0.60 & $0.33,1.10$ & 0.04 & 1 & 1.73 & $1.01,2.95$ \\
\hline \multicolumn{14}{|c|}{ Psychological distress } \\
\hline Crude & 1 & 1.34 & $0.88,2.05$ & 1.04 & $0.67,1.60$ & 0.81 & $0.52,1.27$ & 0.64 & $0.40,1.02$ & 0.008 & 1 & 1.04 & $0.68,1.60$ \\
\hline Model 1 & 1 & 1.37 & $0.89,2 \cdot 10$ & 1.00 & $0.64,1.55$ & 0.80 & $0.51,1.26$ & 0.66 & $0.41,1.05$ & 0.01 & 1 & 0.98 & $0.63,1.52$ \\
\hline \multirow{2}{*}{\multicolumn{14}{|c|}{$\mathrm{BMI} \geq 25 \mathrm{~kg} / \mathrm{m}^{2}$}} \\
\hline & & & & & & & & & & & & & \\
\hline \multicolumn{14}{|c|}{ Depression } \\
\hline Crude & 1 & 0.79 & $0.49,1.28$ & 0.54 & $0.32,0.89$ & 0.71 & $0.44,1.16$ & 0.48 & $0.29,0.80$ & 0.007 & 1 & 1.31 & $0.77,2.24$ \\
\hline Model 1 & 1 & 0.72 & $0.42,1.24$ & 0.50 & $0.29,0.86$ & 0.62 & $0.36,1.07$ & 0.39 & $0.22,0.68$ & 0.002 & 1 & 1.42 & $0.79,2.56$ \\
\hline Model 2 & 1 & 0.74 & $0.42,1.30$ & 0.51 & $0.28,0.91$ & 0.67 & $0.37,1.21$ & 0.45 & $0.24,0.85$ & 0.02 & 1 & 1.23 & $0.64,2.34$ \\
\hline \multicolumn{14}{|l|}{ Anxiety } \\
\hline Crude & 1 & $1 \cdot 14$ & $0.65,2.01$ & 0.77 & $0.42,1.40$ & 0.85 & $0.47,1.54$ & 0.63 & $0.34,1.19$ & 0.09 & 1 & 1.32 & $0.71,2.44$ \\
\hline Model 1 & 1 & 1.20 & $0.66,2.19$ & 0.77 & $0.40,1.45$ & 0.75 & $0.39,1.41$ & 0.60 & $0.31,1.17$ & 0.04 & 1 & 1.45 & $0.76,2.78$ \\
\hline Model 2 & 1 & $1 \cdot 10$ & $0.59,2.05$ & 0.70 & $0.36,1.36$ & 0.71 & $0.37,1.37$ & 0.59 & $0.29,1.17$ & 0.05 & 1 & 1.63 & $0.81,3.28$ \\
\hline Psychologic & & & & & & & & & & & & & \\
\hline Crude & 1 & 0.92 & $0.55,1.53$ & 0.53 & $0.30,0.91$ & 0.64 & $0.38,1.09$ & 0.53 & $0.30,0.91$ & 0.007 & 1 & 1.84 & $1.07,3.17$ \\
\hline Model 1 & 1 & 0.91 & $0.54,1.52$ & 0.52 & $0.30,0.91$ & 0.59 & $0.34,1.01$ & 0.48 & $0.27,0.84$ & 0.002 & 1 & 2.05 & $1.18,3.55$ \\
\hline Model 2 & 1 & 1.28 & $0.73,2.26$ & 0.81 & $0.44,1.49$ & 0.96 & $0.52,1.78$ & 0.87 & $0.45,1.67$ & 0.40 & 1 & 1.18 & $0.61,2.25$ \\
\hline
\end{tabular}

* All women: Q1: <281 mg/d, Q2: $281-<303 \mathrm{mg} / \mathrm{d}$, Q3: 303 to $<325 \mathrm{mg} / \mathrm{d}$, Q4: $325-<356 \mathrm{mg} / \mathrm{d}$, Q5: $\geq 356 \mathrm{mg} / \mathrm{d}$; BMl $<25 \mathrm{~kg} / \mathrm{m}^{2}:$ Q1: $<278 \mathrm{mg} / \mathrm{d}$, Q2: $278-<299 \mathrm{mg} / \mathrm{d}$, Q3: $299-<321 \mathrm{mg} / \mathrm{d}, \mathrm{Q} 4: 321-<353 \mathrm{mg} / \mathrm{d}, \mathrm{Q} 5: \geq 353 \mathrm{mg} / \mathrm{d}$; BMl $\geq 25 \mathrm{~kg} / \mathrm{m}^{2}$ : Q1: $<286 \mathrm{mg} / \mathrm{d}, \mathrm{Q} 2: 286-<310 \mathrm{mg} / \mathrm{d}, \mathrm{Q} 3: 310-<330 \mathrm{mg} / \mathrm{d}, \mathrm{Q} 4: 330-<330 \mathrm{mg} / \mathrm{d}, \mathrm{Q} 5: \geq 359 \mathrm{mg} / \mathrm{d}$. † EAR; women: $265 \mathrm{mg} / \mathrm{d}$.

‡ Depression: model 1: adjusted for adjusted for age, marital status, education, family size, smoking status and anti-psychotic medications, and model 2: additionally adjusted for dietary intake of energy and vitamin $\mathrm{B}_{5}$.

§ Anxiety: model 1: adjusted for marital status, education, smoking status, home ownership and anti-psychotic medications, and model 2: additionally adjusted for dietary intake of energy, fibre, vitamin $B_{1}$ and vitamin $B_{2}$.

II Psychological distress: model 1: adjusted for education and anti-psychotic medications, and model 2: additionally adjusted for energy intake and dietary intake of vitamin $B_{3}$ and $\mathrm{Fe}$.

the accuracy of dietary assessment might be different between normal-weight and overweight individuals. As shown in previous studies, under-reporting of dietary intakes is common among individuals with overweight and obesity ${ }^{(55)}$. Although we controlled for total energy intake, it must be paid attention that such controlling in the analyses might not entirely exclude the effect of energy intake on the associations.

In this study, we found no significant association between dietary $\mathrm{Mg}$ intake and psychological distress in the fully adjusted model. To our knowledge, earlier studies that assessed the contribution of diet to psychological distress have mostly focused on dietary patterns rather than on individual foods and nutrients. For instance, in an Australian cross-sectional study, adherence to a Mediterranean-style diet (rich in $\mathrm{Mg}$ ) was not associated with psychological distress ${ }^{(56)}$. Conversely, Hodge et $a l .{ }^{(57)}$ reported that adherence to a dietary pattern rich in legumes and nuts was inversely associated with psychological distress. Furthermore, in another cross-sectional study, an inverse association was reported between a dietary pattern rich in $\mathrm{Mg}$ and psychological distress among Indian individuals ${ }^{(58)}$. The beneficial effects of these dietary patterns on psychological distress might be mediated through their $\mathrm{Mg}$ content. 
Conflicting findings about $\mathrm{Mg}$ intake in relation to psychological distress might be because of the lack of taking potential confounders into account along with the use of unacceptable tools for assessment of diet or psychiatric disorders in previous studies $^{(56,58)}$. Therefore, further studies are needed to shed light facts in this regard.

The inverse association between $\mathrm{Mg}$ intake and depression plus anxiety might be explained by several mechanisms. Mg as an essential trace element might have a role in different pathways $^{(15)}$. It acts as a cofactor for the synthesis and release of numerous enzymes, neurotransmitters and hormones required for normal neuronal functioning ${ }^{(15,20)}$. Mg has an important role in stability of neurons, such as membrane stability ${ }^{(59,20)}$. Neuron membrane is involved in releasing neurotransmitters affecting intracellular messaging. Therefore, $\mathrm{Mg}$ contributes indirectly to intracellular messaging ${ }^{(60)}$. In addition, owing to a significant association between inflammatory markers and psychiatric disorders, the inhibitory effects of $\mathrm{Mg}$ on secretion of inflammatory markers might be another reason explaining the inverse relationship between $\mathrm{Mg}$ intake and mental disorders ${ }^{(15)}$. The inverse association between $\mathrm{Mg}$ intake and inflammation has been shown in both animal and human studies ${ }^{(15)}$.

This study has several strengths. As far as we know, this is the first study examining the association between dietary $\mathrm{Mg}$ intake and psychiatric disorders in the Middle East. Furthermore, the large sample size of the study, including either sex, should also be considered. However, during the interpretation of our findings, some limitations should be also noticed. The main limitation is the cross-sectional design of our study, which prohibit us inferring causality. Therefore, further prospective studies are needed to confirm our findings. In addition, measurement error is another potential limitation, as is in all dietary assessment methods. Because of the use of FFQ to assess usual dietary intakes, misclassification of study individuals is another concern. However, we used a validated FFQ for assessment of dietary intakes. Furthermore, we cannot exclude residual confounders despite adjusting for a wide range of potential confounders

In conclusion, we found that dietary $\mathrm{Mg}$ intake was associated with lower odds of depression and anxiety among Iranian adults. No significant association was seen between dietary $\mathrm{Mg}$ intake and psychological distress among men and women. Our findings should be confirmed by future prospective studies.

\section{Acknowledgements}

The study was financially supported by Isfahan University of Medical Sciences in collaboration with Tehran University of Medical Sciences. Professor A. E. was supported by a grant from Iran National Science Foundation as well.

J. A.-S., O. S. and A. E. contributed to the conception and design of the study, data collection and statistical analysis and drafting of the manuscript; A. H. K., H. A. and P. A. contributed in data collection and manuscript drafting. All authors read and approved the final manuscript.

None of the authors has any conflicts of interest to declare.

\section{References}

1. Murphy JM, Horton NJ, Laird NM, et al. (2004) Anxiety and depression: a 40-year perspective on relationships regarding prevalence, distribution, and comorbidity. Acta Psychiatr Scand 109, 355-375.

2. Mojtabai R (2011) National trends in mental health disability, 1997-2009. Am J Public Health 101, 2156-2163.

3. Olesen J, Gustavsson A, Svensson M, et al. (2011) The economic cost of brain disorders in Europe. Eur J Neurol 19, 155-162.

4. Sobocki P, Jönsson B, Angst J, et al. (2006) Cost of depression in Europe. J Ment Health Policy Econ 9, 87-98.

5. Baxter A, Scott K, Vos T, et al. (2013) Global prevalence of anxiety disorders: a systematic review and meta-regression. Psychol Med 43, 897-910.

6. Ferrari A, Somerville A, Baxter A, et al. (2013) Global variation in the prevalence and incidence of major depressive disorder: a systematic review of the epidemiological literature. Psychol Med 43, 471-481.

7. Noorbala AA, Bagheri Yazdi SA, Yasamy MT, et al. (2013) Mental health survey of the adult population in Iran. $\mathrm{Br} \mathrm{J}$ Psychiatry 184, 70-73.

8. Saveanu RV \& Nemeroff CB (2012) Etiology of depression: genetic and environmental factors. Psychiatr Clin North Am 35, 51-71.

9. Murakami K \& Sasaki S (2010) Dietary intake and depressive symptoms: a systematic review of observational studies. Mol Nutr Food Res 54, 471-488.

10. Quirk SE, Williams LJ, O'Neil A, et al. (2013) The association between diet quality, dietary patterns and depression in adults: a systematic review. BMC Psychiatry 27, 175.

11. Konttinen H, Männistö S, Sarlio-Lähteenkorva S, et al. (2010) Emotional eating, depressive symptoms and self-reported food consumption: a population-based study. Appetite 54, 473-479.

12. Michels N, Sioen I, Braet C, et al. (2012) Stress, emotional eating behaviour and dietary patterns in children. Appetite 59 , 762-769.

13. Sánchez-Villegas A, Delgado-Rodríguez $\mathrm{M}$, Alonso A, et al. (2009) Association of the Mediterranean dietary pattern with the incidence of depression: the Seguimiento Universidad de Navarra/University of Navarra follow-up (SUN) cohort. Arch Gen Psychiatry 10, 1090-1098.

14. Opie RS, O'Neil A, Itsiopoulos C, et al. (2015) The impact of whole-of-diet interventions on depression and anxiety: a systematic review of randomised controlled trials. Public Health Nutr 18, 2074-2093.

15. Mohamed Salih S, Nallasamy P, Muniyandi P, et al. (2009) Genistein improves liver function and attenuates nonalcoholic fatty liver disease in a rat model of insulin resistance. J Diabetes 1, 278-287.

16. Oliveira LP, de Jesus RP, Freire TO, et al. (2012) Possible molecular mechanisms soy-mediated in preventing and treating nonalcoholic fatty liver disease. Nutr Hosp 27, 991-998.

17. Messina MJ (1999) Legumes and soybeans: overview of their nutritional profiles and health effects. Am J Clin Nutr 70, 439-450.

18. Yary T, Lehto SM, Tolmunen T, et al. (2016) Dietary magnesium intake and the incidence of depression: a 20-year follow-up study. J Affect Disord Mar 15, 94-98.

19. Martínez-González MÁ \& Sánchez-Villegas A (2016) Magnesium intake and depression: the SUN cohort. Magnes Res 29, 102-111.

20. Barra A, Camardese G, Tonioni F, et al. (2007) Plasma magnesium level and psychomotor retardation in major depressed patients. Magnes Res 20, 245-249. 
21. Camardese G, De Risio L, Pizi G, et al. (2012) Plasma magnesium levels and treatment outcome in depressed patients. Nutr Neurosci 15, 78-84.

22. Cheungpasitporn W, Thongprayoon C, Mao MA, et al. (2015) Hypomagnesaemia linked to depression: a systematic review and meta-analysis. Intern Med J 45, 436-440.

23. Adibi P, Keshteli AH, Esmaillzadeh A, et al. (2012) The study on the epidemiology of psychological, alimentary health and nutrition (SEPAHAN): overview of methodology. I Res Med Sci 17, 292-298.

24. Willett W (2013) Nutritional Epidemiology. Oxford: Oxford University Press.

25. Keshteli A, Esmaillzadeh A, Rajaie S, et al. (2014) A dish based semi-quantitative food frequency questionnaire for assessment of dietary intakes in epidemiologic studies in Iran: design and development. Int J Prev Med 5, 29-36.

26. Ghaffarpour M, Houshiar-Rad A \& Kianfar H (1999) The Manual for Household Measures, Cooking Yields Factors and Edible Portion of Foods. Tehran: Nashre Olume Keshavarzy.

27. US Department of Agriculture \& Agricultural Research Service (2005) USDA national nutrient database for standard reference. http://www.ars.usda.gov/ba/bhnrc/ndl

28. Esmaillzadeh A, Keshteli AH, Feizi A, et al. (2013) Patterns of diet-related practices and prevalence of gastroesophageal reflux disease. Neurogastroenterol Motil 25, 831-e638.

29. Esmaillzadeh A, Keshteli AH, Hajishafiee M, et al. (2013) Consumption of spicy foods and the prevalence of irritable bowel syndrome. World J Gastroenterol 19, 6465-6471.

30. Barak F, Falahi E, Keshteli AH, et al. (2015) Adherence to the DASH diet in relation to obesity among Iranian female nurses. Public Health Nutr 18, 705-712.

31. Zaribaf F, Falahi E, Barak F, et al. (2014) Fish consumption is inversely associated with the metabolic syndrome. Eur J Clin Nutr 68, 474-480.

32. Salehi-Abargouei A, Esmaillzadeh A, Azadbakht L, et al. (2016) Nutrient patterns and their relation to general and abdominal obesity in Iranian adults: findings from the SEPAHAN study. Eur J Nutr 55, 505-518.

33. Montazeri A, Vahdaninia M, Ebrahimi M, et al. (2003) The Hospital Anxiety and Depression Scale (HADS): translation and validation study of the Iranian version. Health Qual Life Outcomes 28, 1-14.

34. Schmitz N, Kruse J, Heckrath C, et al. (1999) Diagnosing mental disorders in primary care: the General Health Questionnaire (GHQ) and the Symptom Check List (SCL-90-R) as screening instruments. Soc Psychiatry Psychiatr Epidemiol 34, 360-366

35. Montazeri A, Harirchi AM, Shariati M, et al. (2003) The 12-item General Health Questionnaire (GHQ-12): translation and validation study of the Iranian version. Health Qual Life Outcomes 13, 1-66.

36. Kathleen Mahan L, Escott-Stump S, Raymond JL, et al. (2012) Krause's Food and the Nutrition Care Process, 13th ed. St. Louis, MO: Elsevier/Saunders.

37. Markowitz S, Friedman MA \& Arent SM (2008) Understanding the relation between obesity and depression: causal mechanisms and implications for treatment. Clin Psychol Sci Pract 15, 1-20.

38. Van der Kooy K, van Hout H, Marwijk H, et al. (2007) Depression and the risk for cardiovascular diseases: systematic review and meta-analysis. Int J Geriatr Psychiatry 22, 613-626.

39. Nouwen A, Lloyd CE \& Pouwer F (2009) Depression and type 2 diabetes over the lifespan: a meta-analysis. Response to Mezuk et al. Diabetes 32, 56.
40. Penninx BW, Guralnik JM, Pahor M, et al. (1988) Chronically depressed mood and cancer risk in older persons. I Natl Cancer Inst 90, 1888-1893.

41. Rubio-López N, Morales-Suárez-Varela M, et al. (2016) Nutrient intake and depression symptoms in Spanish children: The ANIVA Study. Int J Environ Res Public Health 22, 13.

42. Li B, Lv J, Wang W, Zhang D, et al. (2016) Dietary magnesium and calcium intake and risk of depression in the general population: a meta-analysis. Aust N Z J Psychiatry 51, 3.

43. Derom ML, Martínez-González MA, del Carmen Sayón-Orea M, et al. (2012) Magnesium intake is not related to depression risk in Spanish university graduates. J Nutr 142, 1053-1059.

44. Hunang JH, Lu YF, Cheng FC, et al. (2012) Correlation of magnesium intake with metabolic parameters, depression and physical activity in elderly type 2 diabetes patients: a crosssectional study. Nutr J 13, 11-41.

45. Sadeghi O, Hassanzadeh-Keshteli A, Afshar H, et al. (2017) The association of whole and refined grains consumption with psychological disorders among Iranian adults. Eur J Nutr 30, $1-15$.

46. Valipour G, Esmaillzadeh A, Azadbakht L, et al. (2017) Adherence to the DASH diet in relation to psychological profile of Iranian adults. Eur J Nutr 56, 309-320.

47. Boyle NB, Lawton CL \& Dye L (2016) The effects of magnesium supplementation on subjective anxiety. Magnes Res $\mathbf{2 9}$, 120-125.

48. Lakhan SE \& Vieira KF (2010) Nutritional and herbal supplements for anxiety and anxiety-related disorders: systematic review. Nutr J 9, 42.

49. Laurin C, Lavoie KL, Bacon SL, et al. (2007) Sex differences in the prevalence of psychiatric disorders and psychological distress in patients with COPD. Chest 132, 148-155.

50. Nolen-Hoeksema S (2012) Emotion regulation and psychopathology: the role of gender. Annu Rev Clin Psychol 8, 161-187.

51. Beer-Borst S, Hercberg S, Morabia A, et al. (2000) Dietary patterns in six European populations: results from EURALIM, a collaborative European data harmonization and information campaign. Eur J Clin Nutr 54, 253-262.

52. O'Doherty Jensen K \& Holm L (1999) Preferences, quantities and concerns: socio-cultural perspectives on the gendered consumption of foods. Eur J Clin Nutr 53, 351-359.

53. Marks GC, Hughes MC \& van der Pols JC (2006) Relative validity of food intake estimates using a food frequency questionnaire is associated with sex, age, and other personal characteristics. J Nutr 136, 459-465.

54. Mcelroy SL, Kotwal R, Malhotra S, et al. (2004) Are mood disorders and obesity related? A review for the mental health professional. J Clin Psychiatry 65, 643-651.

55. Lissner L, Troiano RP, Midthune D, et al. (2007) OPEN about obesity: recovery biomarkers, dietary reporting errors and BMI. Int J Obes (Lond) 31, 956-961.

56. Crichton GE, Bryan J, Hodgson JM, et al. (2013) Mediterranean diet adherence and self-reported psychological functioning in an Australian sample. Appetite 70, 53-59.

57. Hodge A, Almeida OP, English DR, et al. (2013) Patterns of dietary intake and psychological distress in older Australians: benefits not just from a Mediterranean diet. Int Psychogeriatr 25, 456-466.

58. Bhattacharyya M, Marston L, Walters K, et al. (2014) Psychological distress, gender and dietary factors in South Asians: a cross-sectional survey. Public Health Nutr 17, 1538-1546.

59. Nechifor M (2009) Magnesium in major depression. Mag Res 22, 163-166.

60. de Baaij JH, Hoenderop JG \& Bindels RJ (2015) Magnesium in man: implications for health and disease. Physiol Rev 95, 1-46. 